\title{
Physical Activity for Health-An Overview and an Update of the Physical Activity Guidelines of the Italian Ministry of Health
}

\author{
Giuseppe Musumeci \\ Department of Biomedical and Biotechnological Sciences, Human Anatomy and Histology Section, \\ School of Medicine, University of Catania, Via S. Sofia 87, 95123 Catania, Italy; g.musumeci@unict.it; \\ Tel.: +39-095-378-2043; Fax: +39-095-378-2034 \\ Academic Editor: Moataz Eltoukhy \\ Received: 23 May 2016; Accepted: 17 June 2016; Published: 23 June 2016
}

\begin{abstract}
Physical activity for health is the topic chosen for the third editorial of this newly launched journal. The aim of this editorial is to illustrate and comment on the physical activity guidelines of the Italian Ministry of Health.
\end{abstract}

Keywords: physical activity; health; pregnant women; children; old people; diseases

\section{Introduction}

The expression mens sana in corpore sano, which means "a healthy mind in an healthy body", stems from a sentence written by Decimo Giunio Giovenale. In the Western world, the phrase is widely used in sporting and educational contexts to express the concept that physical exercise is an important or essential part of mental and psychological well-being. The Latin poet, in the first century A.D., criticizes men who strive to obtain wealth and fame, an activity that in his view is ephemeral and harmful. Thus, Giovenale thought that only two qualities for which it was worth invoking the gods existed: the health of the mind and the health of the body (Orandum est ut sit mens sana in corpore sano). Today, the phrase, popular in sports clubs since the beginning of the last century, has taken on quite a different meaning, influenced by today's conventional wisdom: keeping your body in a good shape also maintains the brain's health. It has been demonstrated that physical activity prevents neurodegenerative diseases, such as Alzheimer's disease and other disorders [1]. Moving daily has positive effects on people's physical and mental health: exercise is medicine. The human body was not meant for inactivity. Movement is inherently required, and regular physical activity, even if moderate, helps to improve all aspects of quality of life. In contrast, poor physical activity is implicated in the onset of some of the most common disorders and diseases: type 2 diabetes, cardiovascular disease (heart attack, myocardial infarction, stroke, and heart failure), and tumors [2,3].

\section{The Numbers}

Italy currently has no national health monitoring or surveillance system for physical activity. The country has adopted national recommendations, using cut-off points for adults reaching recommended physical activity levels as defined by the United States Centers for Disease Control and Prevention (CDC) and the American College of Sports Medicine (ACSM) [4]. In Italy, 30\% of adults between 18 and 69 years, in everyday life, perform less physical activity than recommended and can be defined as sedentary. In particular, the risk of physical inactivity increases with age, and is higher among people with low educational attainment and economic difficulties. The situation is better in the regions of Northern Italy, but worse in the southern regions, as previously described in national data for the years 2010-2013 from the survey by the Italian Ministry of Health's Behavioral Risk Factor 
Surveillance System (Progressi delle Aziende Sanitarie per la Salute in Italia (PASSI) [4]. According to ISTAT (Italian National Institute of Statistics), in 2010 in Italy, 38\% of people older than three years said they did not practice physical activity, in daily life, in sports, or in other forms. According to the "Okkio alla salute project", only 1 child out of 10 performed physical activity appropriately for their age and about 1 out of 4 children (26\%), at the time of detection, stated that they had not engaged in any physical activity the day before the survey [5]. As in other European countries, physical activity of the population in Italy has declined in parallel with the great changes of work and organization of the urban environment. On the one hand, there is the development of automation in domestic work and the social downgrading of manual labor, with the dominance of motorized transport and the reduction of space and safety for pedestrians and cyclists. Together with these latter factors, the free space allowed for children's games and for team and individual sports has decreased. These activities now have allotted places whose accessibility is limited; they have a cost, not just monetary, often not affordable for most people. Moreover, the value that is socially assigned to physical activity and other factors, such as parental models and the influence attributed to physical activity in the school curriculum, play a role. Today, in Italian schools, there are only two hours a week of physical activity for the young students, and this is done too often without sufficiently qualified instructors [6,7]. These obstacles make a programmed activity with exercise and training movements difficult.

\section{The Benefits of Physical Activity}

Daily moving has positive effects on the physical and mental health of any person. Plenty of studies [1-3,8-11] confirms its beneficial effects and discloses that physical activity

- improves glucose tolerance and reduces the risk of type 2 diabetes;

- prevents hypercholesterolemia and hypertension and reduces the levels of blood pressure and cholesterol;

- decreases the risk of developing heart disease and several cancers, such as those of the colon and breast;

- reduces the risk of premature death, especially that caused by heart attacks and other heart diseases;

- prevents and reduces the risk of osteoporosis and fractures, as well as musculoskeletal disorders (e.g., back pain);

- prevents and reduces the risk of osteoarthritis and other rheumatic diseases;

- reduces the symptoms of anxiety, stress, physical limitations, fatigue, and depression;

- prevents, especially among children and young people, risky behaviors such as the use of tobacco, alcohol, unhealthy diets, and bullying and promotes psychological well-being by developing self-esteem, making the management of anxiety and stressful situations easier; and

- $\quad$ produces an energy expenditure and decreases the risk of obesity.

\section{Which Physical Activity?}

When anybody talks about physical activity, it is not an uncommon mistake to confuse it with sport. However, the World Health Organization (WHO) defines physical activity as any body movement produced by skeletal muscles that requires energy expenditure. This definition covers therefore not only sports, but also the work of those performing manual work and normal movements of daily living, such as walking, cycling, dancing, playing, gardening, and housework [11-14] (Figure 1). For physical activity, therefore, it is not necessary to find time to specifically dedicate to physical activity. You can find opportunities to engage in physical movement at all times of the day in normal daily activities. This is a plea to do a bit of exercise. A bit of activity is better than none. The benefits begin as soon as you start to become more active. 

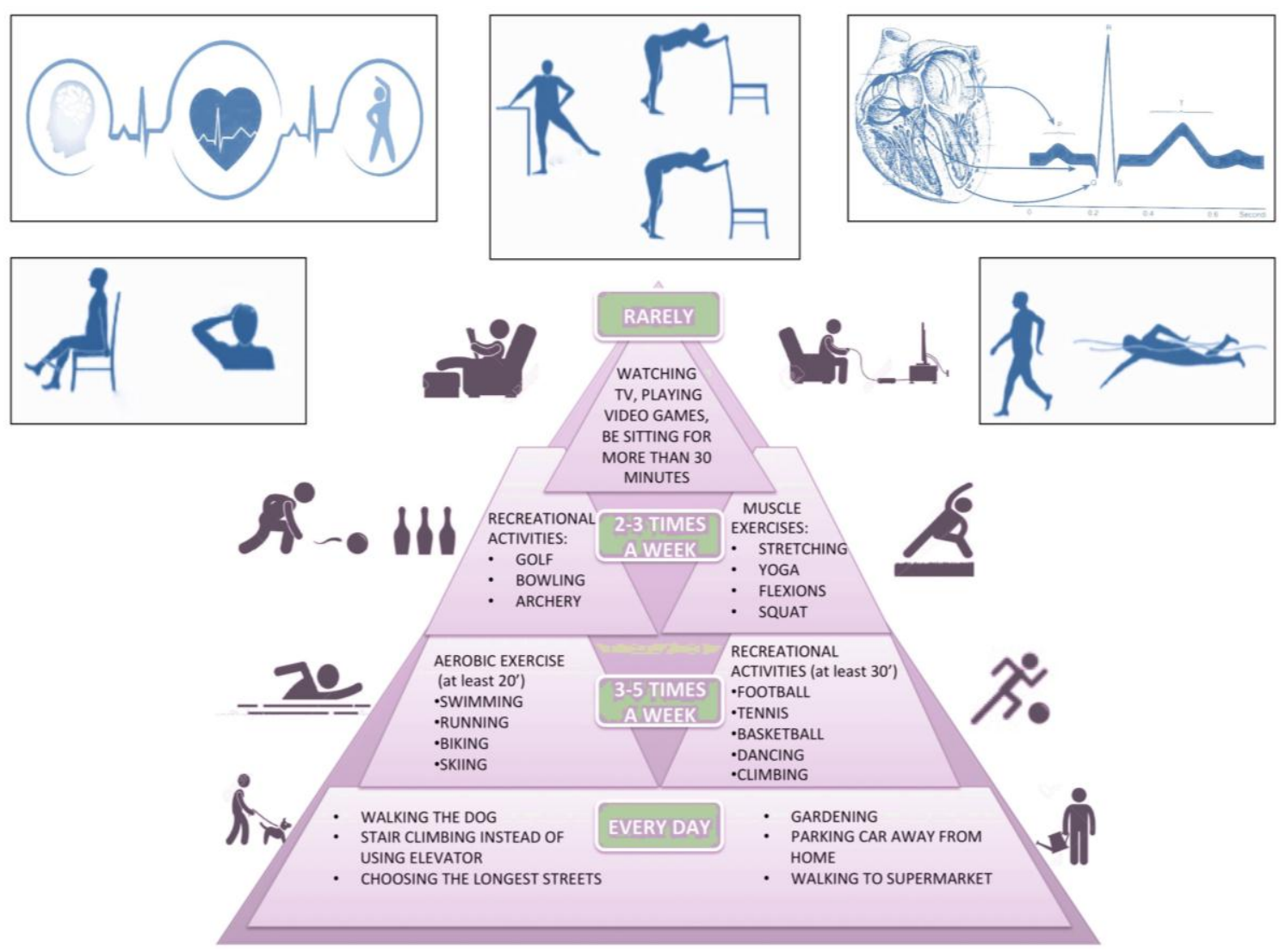

Figure 1. Infographic of physical activity guidelines during our normal life in one week, suggested by the World Health Organization (WHO), to prevent the onset of diseases related to a sedentary lifestyle. This graphic represents the pyramid of physical activity recommendations. At the base are the suggestions for everyday activities, and at the top are activities to perform rarely.

\section{How to Move?}

There is no definite level of physical activity that is valid for any person, nor is it easy to measure the amount of movement made. Nevertheless, in 2010, the WHO [12] has tried to give clear indications that apply to all, establishing a minimum amount of physical activity for three age groups:

Children (5-17 years): at least $60 \mathrm{~min}$ a day of moderate-vigorous activity, including strength exercises, consisting of, e.g., games requiring movement or sports activities, at least three times a week.

Adults (18-64 years): at least $150 \mathrm{~min}$ per week of moderate activity or $75 \mathrm{~min}$ of vigorous activity, with exercises strengthening major muscle groups, carried out at least twice a week.

Seniors (65 years and above): the indications are the same as adults, taking care to also carry out activities geared to balance in order to prevent falls. Whoever is unable to follow the recommendations in full should do physical activity at least three times a week and adopt an appropriately active lifestyle.

In any case, it was shown that there is no clear threshold below which physical activity is not beneficial to health. A transition from a sedentary lifestyle to a level of activity even lower than the levels indicated by the guidelines is therefore very important. It is also important to make a personal commitment to change the context in which we live in order to support the changes needed to make it easier to adopt a healthy and active lifestyle in our own cities, whether studying or working [11-14].

\section{Children}

For children and young people, participation in games and other physical activities, both at school and during free time, is essential for healthy bones and joints and muscular system development, psychological and social well-being, the control of body weight, and the proper functioning of the 
cardiovascular and respiratory systems. In addition, sport and physical activity can help prevent the onset of behavior unfavorable to health, such as the habit of smoking and alcohol and drug use. The WHO recommends at least $60 \mathrm{~min}$ a day of moderate-vigorous activity [12].

To better promote the welfare of children in Italy, the HEPA (a European network for the promotion of health-enhancing physical activity) (Table 1), in agreement with the Ministry of Education, Universities and Research, the Italian Olympic Committee (CONI), and the Presidency of the Council of Ministers, established a promotion program to promote physical education in primary school in Italy in 2013. The aims of the intervention were to motivate young children to be more physically active, ensure $2 \mathrm{~h}$ per week of physical education, review the governance model for PE in schools to ensure greater synergy and coordination between the project coordinators, and ensure that all primary schools in Italy were engaged in the program on some level [13].

Table 1. Objectives and principles of the HEPA (European network for the promotion of health-enhancing physical activity).

\begin{tabular}{ll}
\hline \multicolumn{1}{c}{ Objectives } & \multicolumn{1}{c}{ Principles } \\
\hline $\begin{array}{l}\text { Promote a better understanding of health-enhancing physical } \\
\text { activity and give a stronger voice to physical activity } \\
\text { promotion in health policy and in other relevant sectors in } \\
\text { Europe, including support for workforce development. }\end{array}$ & $\begin{array}{l}\text { Focus on population-based approaches for the promotion of } \\
\text { health-enhancing physical activity using the best available } \\
\text { scientific evidence. }\end{array}$ \\
\hline $\begin{array}{l}\text { Develop, support, and disseminate effective strategies and } \\
\text { multi-sectoral approaches in the promotion of } \\
\text { health-enhancing physical activity. }\end{array}$ & $\begin{array}{l}\text { Emphasis on the importance of monitoring and evaluation; } \\
\text { encouragement of the development of standardized } \\
\text { measurement methods and systematic research. }\end{array}$ \\
\hline $\begin{array}{l}\text { Foster the preservation and creation of social and physical } \\
\text { environments as well as values and lifestyles supportive of } \\
\text { health-enhancing physical activity. }\end{array}$ & $\begin{array}{l}\text { Encouragement of the ongoing exchange, dissemination, and } \\
\text { sharing of experience and knowledge. }\end{array}$ \\
\hline $\begin{array}{l}\text { Together with other relevant institutions and organizations, } \\
\text { improve coordination in physical activity promotion across } \\
\text { sectors and administrative structures. }\end{array}$ & $\begin{array}{l}\text { Support of cooperation, partnerships, and collaboration with } \\
\text { other related sectors, networks, and approaches. }\end{array}$ \\
\hline
\end{tabular}

\section{Pregnant Women}

Physical activity during pregnancy is far from being contraindicated. If carried out observing several precautions, it can be beneficial for the mother and the child. In fact, it increases the ability to transport oxygen in the blood and nutrients that the fetus needs. In addition, exercise increases the efficiency of the cardiovascular and respiratory systems, improves blood flow in the legs, thus reducing swelling, and reduces the episodes of pain, cramps, and fatigue. Regular movement, as well, limits the increase in body weight, decreasing the risk of gestational diabetes. However, it must not be overdone. For healthy women, 30-40 min a day of physical activity at low intensity are enough, i.e. walking, swimming, or gymnastics. After the eighth month of pregnancy, however, you must take caution, performing exercises to improve breathing and relaxation only [15].

\section{Elderly People}

Even for elderly people, exercise is particularly useful. Daily movement retards aging, prevents osteoporosis, and helps to prevent disability, depression, and mental impairment. It prevents the risk of accidental falls by improving balance and coordination.

According to the WHO, 150 min per week of moderate activity are enough, and activities geared to improving equilibrium to prevent falls are preferred [16-19]. For the majority of the aging population, the goals are not related to athletic performance, but rather to daily living activities. Flexibility programs can increase the functional range of motion and reduce the risk of injury. Joint flexibility may decrease with age, affecting normal daily function; elderly adults could maintain their fitness by improving flexibility through stretching exercises [9]. 


\section{People Who Have no Time}

Not everyone can devote part of the day to physical activity. However, this does not mean that it is not possible to carry out the right amount of movement. One should simply stay active at every opportunity [9]. For example, one can do the following:

- go to work or to school on foot or by bicycle;

- when using public transportation, get off one stop earlier and finish on foot;

- do not take the car to make short trips, and, when you use it, park a little farther from the destination;

- take the stairs instead of the elevator;

- walk the dog;

- do gardening or housework;

- go dancing;

- train at home listening to music (or a home exercise program); and

- play with children, possibly outdoors or through activities that require physical movement.

\section{People Who Have Diseases}

People who have diseases such as diabetes, sarcopenia of cirrhosis, hypertension, and obesity can benefit greatly from regular physical activity [19]. Moreover, people suffering from other diseases, such as cardiovascular ones, can benefit from the regular practice of physical activity, much like a pharmacological treatment that, if done properly, aids in the management of the disease. Often, the practice of physical activity is at least as effective as drugs in not only the prevention, but also the treatment of several diseases such as heart failure, diabetes, and depression. The manner and timing should always be agreed with the appropriate physician.

\section{Conclusions}

Exercise can be beneficial both physically and psychologically. Regular exercise has great importance in maintaining good health, balance, and posture; indeed, inactivity is a risk factor for several chronic diseases. Moreover, physical activity is a good way to socialize and an excellent anti-stress agent-not to mention the aesthetic benefits for our body. Physical activity also helps to reduce constipation. It is useful and highly recommended by the WHO, ACSM, HEPA, and the Italian Ministry of Health's Physical Activity Guidelines to do physical activity at least three times a week for about one to two hours of training, in effect taking at least 10,000 steps a day, as suggested by the American Heart Association [20]. Moreover, in order to have a healthy lifestyle, we must also know how to handle the other 22 remaining hours of the day in a healthy way: for example, having a healthy and good nutrition, avoiding medication, sleeping well, moving as much as possible, and having restful sleep. For improved physical performance, using an activity tracker for monitoring is recommended to ensure your daily activities meet your individual needs. Activity trackers can constantly monitor steps taken, sleep patterns, and heart rate [21]. The nutritional aspects associated with physical activity are fundamental in daily life [22-26] to help improve our body despite an active and stressful day. As Patrick Holford said in his book "the health begins at the table".

The exercise regimen must be mild to moderate and mostly "adapted" personalized, or "tailor-made" since the level of exercise will be dependent on the tolerability of the individual, because the body of each individual responds in a different way. For this reason, each trainer should elaborate and personalize a trainee's diet and training program in accordance with the trainee's skill level; moreover, novices should be monitored by a specialized trainer. No do-it-yourself training should be allowed, because physical activity, when done poorly, can do much more harm than sedentary life. As stated by the American College of Sports Medicine, physical activity should be your prescription for health, as non-pharmacologic treatment, since exercise is medicine. 
Acknowledgments: A special thank goes to our editorial advisors, eminent scientists in these fields whose experience and important suggestions guided us in this great enterprise, our excellent editorial board members, whose depth of experience cover a very broad spectrum of morphology and kinesiology; the assistant editors that, day after day, thanks to their valuable contributions, made this journal possible; and the peer reviewers. On behalf of the editorial board, we appreciate the voluntary contribution that each peer reviewer has given to maintaining high journalistic standards and ensuring rapid publication. I sincerely thank them in advance for offering their precious time for the participation in the review process.

Conflicts of Interest: The author declares no conflict of interest.

\section{References}

1. Dao, A.T.; Zagaar, M.A.; Salim, S.; Eriksen, J.L.; Alkadhi, K.A. Regular exercise prevents non-cognitive disturbances in a rat model of Alzheimer's disease. Int. J. Neuropsychopharmacol. 2014, 17, 593-602. [CrossRef] [PubMed]

2. Garber, C.E.; Blissmer, B.; Deschenes, M.R.; Franklin, B.A.; Lamonte, M.J.; Lee, I.M.; Nieman, D.C.; Swain, D.P. American College of Sports Medicine. American College of Sports Medicine position stand. Quantity and quality of exercise for developing and maintaining cardiorespiratory, musculoskeletal, and neuromotor fitness in apparently healthy adults: Guidance for prescribing exercise. Med. Sci. Sports Exerc. 2011, 43, 1334-1359. [PubMed]

3. Haskell, W.L.; Lee, I.M.; Pate, R.R.; Powell, K.E.; Blair, S.N.; Franklin, B.A.; Macera, C.A.; Heath, G.W.; Thompson, P.D.; Bauman, A. Physical activity and public health: Updated recommendation for adults from the American College of Sports Medicine and the American Heart Association. Med. Sci. Sports Exerc. 2007, 39, 1423-1434. [CrossRef] [PubMed]

4. La Sorveglianza PASSI. Rome: National Centre for Epidemiology, Surveillance and Health Promotion (CNESPS) of the Italian National Health Institute (ISS); 2013. Available online: http:/ / www.epicentro.iss.it/ passi/rapporto2013/AttivitaFisica.asp (accessed on 8 July 2015).

5. Pinnelli, A.; Fiori, F. Obesity among the adult population in Italy. Epidemiol. Prev. 2011, 35, $111-117$. [PubMed]

6. Trovato, F.M.; Roggio, F.; Szychlinska, M.A.; Borzì, F.; Musumeci, G. Clinical kinesiology and posturology applied to a group of Italian students. A morphological observational study. J. Funct. Morphol. Kinesiol. 2016, 1, 16-29. [CrossRef]

7. Romano Spica, V.; Giampaoli, S.; di Onofrio, V.; Liguori, G. Safety of sports facilities and training of graduates in physical education. Ann. Ig. 2015, 27, 3-10. [PubMed]

8. Aiello, F.C.; Trovato, F.M.; Szychlinska, M.A.; Imbesi, R.; Castrogiovanni, P.; Loreto, C.; Musumeci, G. Molecular links between diabetes and osteoarthritis: The role of physical activity. Curr. Diabetes Rev. 2015. Epub ahead of print.

9. Musumeci, G. The effects of exercise on physical limitations and fatigue in rheumatic diseases. World J. Orthop. 2015, 6, 762-769. [CrossRef] [PubMed]

10. Trovato, G.M.; Pace, P.; Salerno, S.; Trovato, F.M.; Catalano, D. Pain assessment in fibromyalgia and rheumatoid arthritis: Influence of physical activity and illness perception. Clin. Ter. 2010, 161, 335-339. [PubMed]

11. Musumeci, G.; Trovato, F.M.; Pichler, K.; Weinberg, A.M.; Loreto, C.; Castrogiovanni, P. Extra-virgin olive oil diet and mild physical activity prevent cartilage degeneration in an osteoarthritis model. An "in vivo" and "in vitro" study on lubricin expression. J. Nutr. Biochem. 2013, 24, 2064-2075. [CrossRef] [PubMed]

12. World Health Organization (WHO). Global Recommendations on Physical Activity for Health; World Health Organization: Geneva, Switzerland, 2010.

13. Sport di Classe. Educazione Fisica Nella Scuole Primaria. Rome: Italian National Olympic Committee (CONI); 2013 (in Italian). Available online: http://www.progettosportdiclasse.it/ (accessed on 9 and 22 July 2015).

14. Castrogiovanni, P.; Musumeci, G. Which is the best physical treatment for osteoarthritis? J. Funct. Morphol. Kinesiol. 2016, 1, 54-68. [CrossRef]

15. Bisson, M.; Lavoie-Guénette, J.; Tremblay, A.; Marc, I. Physical activity volumes during pregnancy: A systematic review and meta-analysis of observational studies assessing the association with infant's birth weight. AJP Rep. 2016, 6, 170-197. [CrossRef] [PubMed] 
16. Paterson, D.H.; Warburton, D.E. Physical activity and functional limitations in older adults: A systematic review related to Canada's Physical Activity Guidelines. Int. J. Behav. Nutr. Phys. Act. 2010, 7. [CrossRef] [PubMed]

17. Chodzko-Zajko, W.J.; Proctor, D.N.; Fiatarone Singh, M.A.; Minson, C.T.; Nigg, C.R.; Salem, G.J.; Skinner, J.S. American college of sports medicine position stand. Exercise and physical activity for older adults. Med. Sci. Sports Exerc. 2009, 41, 1510-1530. [CrossRef] [PubMed]

18. Musumeci, G.; Castrogiovanni, P.; Trovato, F.M.; Imbesi, R.; Giunta, S.; Szychlinska, M.A.; Loreto, C.; Castorina, S.; Mobasheri, A. Physical activity ameliorates cartilage degeneration in a rat model of aging: A study on lubricin expression. Scand. J. Med. Sci. Sports 2015, 25, 222-230. [CrossRef] [PubMed]

19. Trovato, F.M.; Aiello, F.C.; Larocca, L.; Taylor-Robinson, S.D. The role of physical activity and nutrition in the sarcopenia of cirrhosis. J. Funct. Morphol. Kinesiol. 2016, 1, 118-125. [CrossRef]

20. Musumeci, G. The effect of mechanical loading on articular cartilage. J. Funct. Morphol. Kinesiol. 2016, 1, 154-161. [CrossRef]

21. Kooiman, T.J.; Dontje, M.L.; Sprenger, S.R.; Krijnen, W.P.; van der Schans, C.P.; de Groot, M. Reliability and validity of ten consumer activity trackers. BMC. Sports Sci. Med. Rehabil. 2015, 7. [CrossRef] [PubMed]

22. Musumeci, G.; Trovato, F.M.; Imbesi, R.; Castrogiovanni, P. Effects of dietary extra-virgin olive oil on oxidative stress resulting from exhaustive exercise in rat skeletal muscle: A morphological study. Acta Histochem. 2014, 116, 61-69. [CrossRef] [PubMed]

23. Catalano, D.; Trovato, G.M.; Pace, P.; Martines, G.F.; Trovato, F.M. Mediterranean diet and physical activity: An intervention study. Does olive oil exercise the body through the mind? Int. J. Cardiol. 2013, 168, 4408-4409. [CrossRef] [PubMed]

24. Trovato, G.M. Behavior, nutrition and lifestyle in a comprehensive health and disease paradigm: Skills and knowledge for a predictive, preventive and personalized medicine. EPMA J. 2012, 3. [CrossRef] [PubMed]

25. Trovato, F.M.; Catalano, D.; Musumeci, G.; Trovato, G.M. 4Ps medicine of the fatty liver: The research model of predictive, preventive, personalized and participatory medicine-recommendations for facing obesity, fatty liver and fibrosis epidemics. EPMA J. 2014, 5. [CrossRef] [PubMed]

26. Trovato, F.M.; Martines, G.F.; Brischetto, D.; Catalano, D.; Musumeci, G.; Trovato, G.M. Fatty liver disease and lifestyle in youngsters: Diet, food intake frequency, exercise, sleep shortage and fashion. Liver Int. 2016, 36, 427-433. [CrossRef] [PubMed]

(C) 2016 by the author; licensee MDPI, Basel, Switzerland. This article is an open access article distributed under the terms and conditions of the Creative Commons Attribution (CC-BY) license (http:/ / creativecommons.org/licenses/by/4.0/). 